\title{
Opinion
}

\section{Utilizing systems biology to unravel stomatal function and the hierarchies underpinning its control}

\author{
David B. Medeiros ${ }^{1}$, Danilo M. Daloso², Alisdair R. Fernie ${ }^{2}$ Zoran Nikoloski $^{3}$ \& Wagner L. Araújo ${ }^{1}$ \\ ${ }^{1}$ Max-Planck Partner Group, Departamento de Biologia Vegetal, Universidade Federal de Viçosa, Viçosa, Minas Gerais, Brazil, \\ ${ }^{2}$ Central Metabolism Group and ${ }^{3}$ Systems Biology and Mathematical Modeling Group, Max Planck Institute of Molecular \\ Plant Physiology, Potsdam-Golm, Germany
}

\begin{abstract}
Stomata control the concomitant exchange of $\mathrm{CO}_{2}$ and transpiration in land plants. While a constant supply of $\mathrm{CO}_{2}$ is need to maintain the rate of photosynthesis, the accompanying water losses must be tightly regulated to prevent dehydration and undesired metabolic changes. The factors affecting stomatal movement are directly coupled with the cellular networks of guard cells. Although the guard cell has been used as a model for characterization of signaling pathways, several important questions about its functioning remain elusive. Current modeling approaches describe the stomatal conductance in terms of relatively few easy-tomeasure variables being unsuitable for in silico design of genetic manipulation strategies. Here, we argue that a system biology approach, combining modeling and high-throughput experiments, may be used to elucidate the mechanisms underlying stomata control and to determine targets for modulation of stomatal responses to environment. In support of our opinion, we review studies demonstrating how highthroughput approaches have provided a systems-view of guard cells. Finally, we emphasize the opportunities and challenges of genome-scale modeling and large-scale data integration for in silico manipulation of guard cell functions to improve crop yields, particularly under stress conditions which are of pertinence both to climate change and water use efficiency.
\end{abstract}

\section{INTRODUCTION}

Stomata are microscopic pores formed by pairs of specialized epidermal guard cells, which control the essential exchange of $\mathrm{CO}_{2}$ with the environment concomitantly with transpiration in land plants. Although plants are in constant need of sufficient quantities of $\mathrm{CO}_{2}$ to maintain their photosynthetic rates, the water losses associated with the $\mathrm{CO}_{2}$ entry must also be strictly regulated to prevent dehydration and the subsequent unfavourable changes of metabolic state that this invokes. Furthermore, the influx of $\mathrm{CO}_{2}$ and the absorption of minerals depend highly on the availability of water, which is usually a major limiting factor for the development and growth of terrestrial plants. For these reasons, most terrestrial

Correspondence: W. L. Araújo. Fax: +55 31 3899.2580; e-mail: wlaraujo@ufv.br plants are coated with a water-impermeable cuticle layer that prevents evaporation and water loss (Bessire et al. 2007; Schreiber 2010; Buschhaus \& Jetter 2011). Accordingly, the majority of water lost to transpiration, and $\mathrm{CO}_{2}$ absorption for that matter, occurs through stomatal pores rendering the stomata as the main control point, which regulates the flow of gases between plants and atmosphere (Schroeder et al. 2001).

Changes in guard cell metabolism can regulate the magnitude of the pore size in response to a range of environmental and endogenous plant stimulus (Kim et al. 2010). This regulation allows plants to occupy habitats with fluctuating environmental conditions. Therefore, it has been postulated that stomata must be important contributors to speciation and evolutionary adaptation (Hetherington \& Woodward 2003). Moreover, stomatal behaviour and stomatal density are of fundamental importance not only for individual plant performance, but also for crop productivity and the terrestrial $\mathrm{CO}_{2}$ and water cycles (Buckley \& Mott 2013; Schroeder et al. 2013).

Stomatal pores open in response to an increase in guard cell volume driven by influx of water, which in turn is the result of a decrease in the water potential of the guard cell. Conversely, during stomatal closure, an efflux of osmolytes from guard cells is necessary with an associated increase in guard cell water potential, leading to efflux of water (Schroeder et al. 2001; Kim et al. 2010; Araújo et al. 2011a,c). Therefore, water potential is one of the key determinants of stomatal movements that is opening and closing.

In addition to the control of water loss, stomatal movements directly affect $\mathrm{CO}_{2}$ assimilation in response to environmental cues by integrating a variety of stimuli, such as: light, vapour pressure deficit (VPD), abscisic acid (ABA) and $\mathrm{CO}_{2}$ concentration (Blatt 2000; Hetherington \& Woodward 2003; Shimazaki et al. 2007; Kim et al. 2010; Hubbard et al. 2012). Although guard cells have often been used as a model system in which to discover ABA receptors (Liu et al. 2007; Pandey et al. 2009; Park et al. 2009) and for the in vitro characterization of the ABA signalling pathway (Fujii et al. 2009), several important questions about guard cell functioning, particularly under suboptimal conditions, remain elusive.

For over a century, guard cells have been extensively studied, and considerable efforts have been made to better 


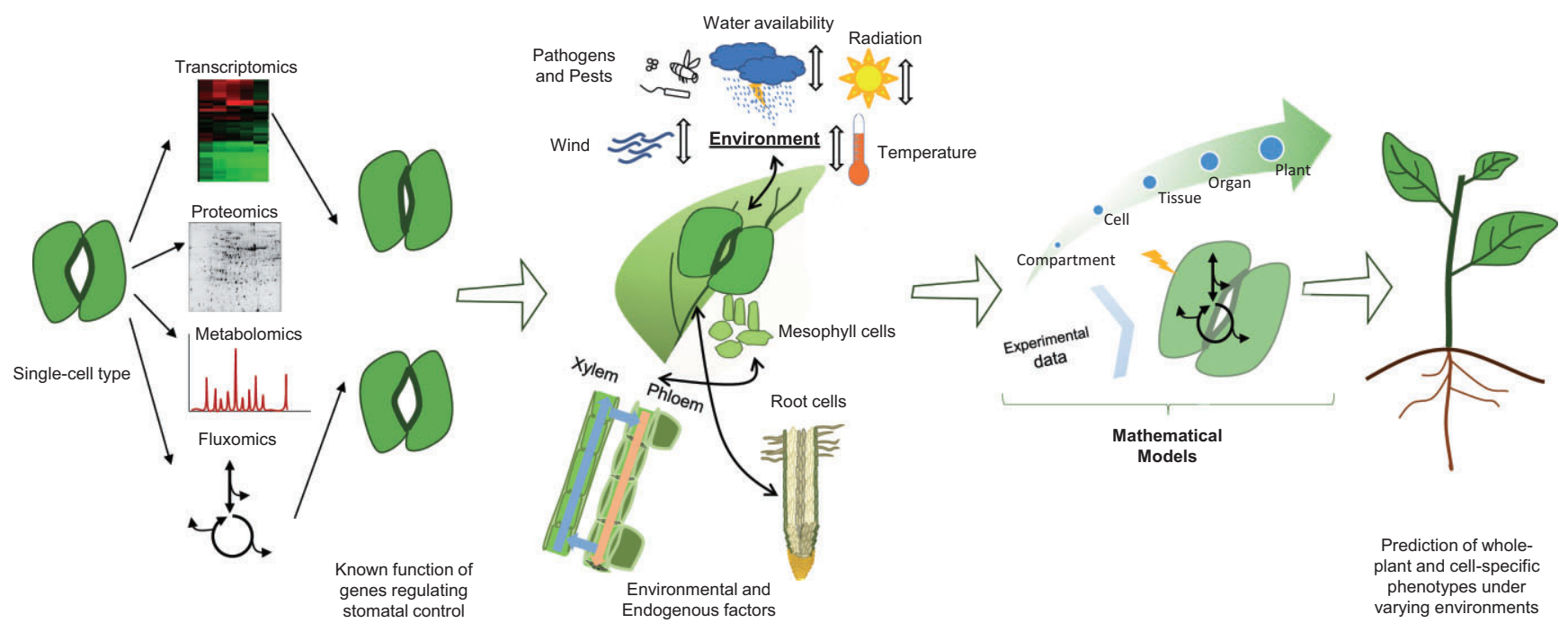

Figure 1. Schematic representation showing how systems analyses and modelling can help the knowledge of molecular hierarchy undergoing stomatal movements and in predictions about phenotypes. The system biology approaches (transcriptomics, proteomics, metabolomics, fluxomics and others) may aid the understanding of unknown questions still unclear about stomatal movements coupling with experimental data from interactions between guard cell - environmental and guard cell - endogenous signals from different cell types that, together with the feedback loops those interactions determine the integrated and coordinated plant behaviour. These data can be grouped in mathematical models to stomatal response and associated with reverse engineering will allow to provide biotechnological targets for generation of improved crop yields and to predict the phenotype under varying environments.

understand their structure, development and physiology (Bessey 1898; Bergmann \& Sack 2007; Mott 2009; Berry et al. 2010; Casson \& Hetherington 2010; Kim et al. 2010; Dow \& Bergmann 2014). In addition, the relative ease of the isolation of the guard cells, which gate the stomatal pore, has facilitated experimental interrogation contributing to the increase in the understanding of these cells relative to other plant cell types (Hetherington \& Brownlee 2004; Israelsson et al. 2006; Kim et al. 2010). These advances have rendered the guard cell as one of the best studied plant cell models for membrane transport, signalling and homeostasis (Blatt 2000; Roelfsema \& Hedrich 2010; Hills et al. 2012).

Thorough understanding of stomatal behaviour and its regulation represents an important step towards obtaining plants with better water-use efficiency, which can be defined as the carbon fixed per unit of water (Lawson \& Blatt 2014; Lawson et al. 2014; Way et al. 2014). Here, our first aim was to focus on high-throughput studies that have recently made considerable progress in elucidating the molecular and genetic bases underlying stomatal function and movement. However, the complexity of interactions involved in regulatory processes ranging from metabolite transport to the cellautonomous metabolic and buffering activities of guard cells remains the main barrier to understand the regulatory networks governing stomatal movement (Blatt et al. 2013). In this context, we suggest that a systems biology approach offers itself as a comprehensive way to aid in elucidation of the mechanisms governing stomatal function and the molecular hierarchies underpinning the stomata control. Furthermore and given that systems biology approaches necessitate data-driven modelling to integrate datasets capturing various read-outs of the cell as well as to generate and validate (or refute) hypotheses, they can also ultimately be used to predict biotechnological targets for the manipulation of stomatal behaviour. To this end, our second aim was to outline the steps that are prerequisites for coupling reverse engineering of stomatal responses with in silico design and modelling in order to direct genetic manipulation for improved crop yield and water-use efficiency (Fig. 1). We additionally suggest an alternative approach to those commonly used to illuminate stomatal behaviour and in doing so hope to bridge the gap between ecophysiological and molecular views of this important cell-to-environment interaction.

\section{Why apply the systems biology approach to study stomatal function?}

Over the last 20 years we have witnessed an increasing interest in the understanding of the molecular mechanisms by which guard cells sense and respond to stimuli such as ABA, plant water status, light, $\mathrm{CO}_{2}$, temperature and humidity. As a consequence, guard cells have become an important model for studies of membrane transport and cell signalling (Assmann 2010). Advances in our understanding over this time period are mostly due to the identification and characterization of mutants deficient in stomatal closing and opening coupled with the currently challenging, but all the same feasible, isolation and screening of large populations of guard cells, employed in various high-throughput technologies (Table 1).

Several seminal studies and numerous reviews (Tallman 2004; Shimazaki et al. 2007; Kim et al. 2010; Meyer et al. 2010; Araújo et al. 2011a; Song et al. 2014), point out that stomatal 


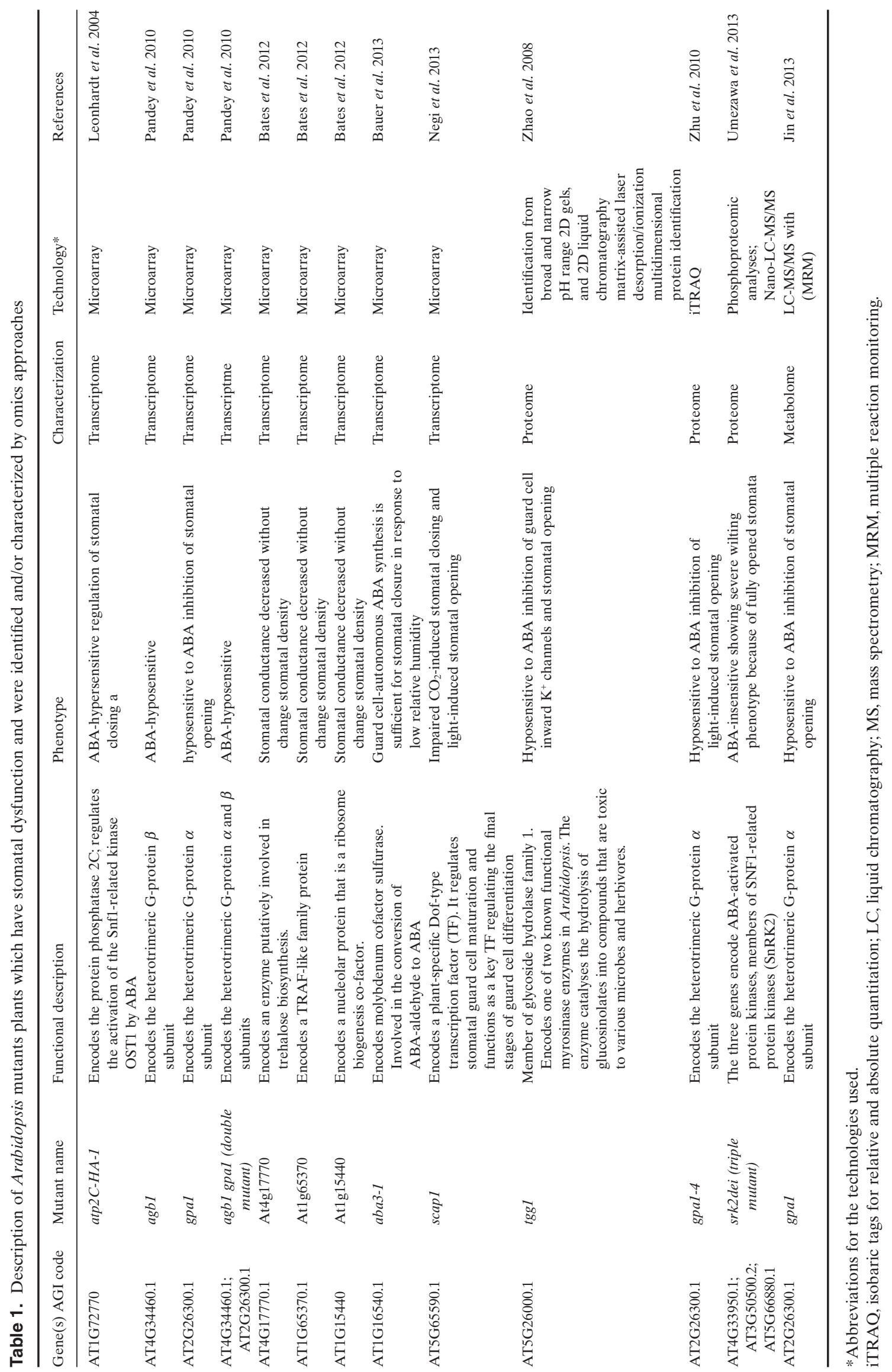


- Light quantity

- Light quality blue, red

- $\mathrm{CO}_{2}$ concentration high $\mathrm{CO}_{2}$, low $\mathrm{CO}_{2}$

- $\mathrm{O}_{2}$ concentration?

- Ions $\mathrm{K}^{+}, \mathrm{Cl}^{-}, \mathrm{NO}_{3}{ }^{-}, \mathrm{Ca}^{+2}$

- Secondary messengers $\mathrm{NO}, \mathrm{H}_{2} \mathrm{O}_{2}$

- Metabolites Mal, Fum, Succ

- Hormones ABA, ET, JA

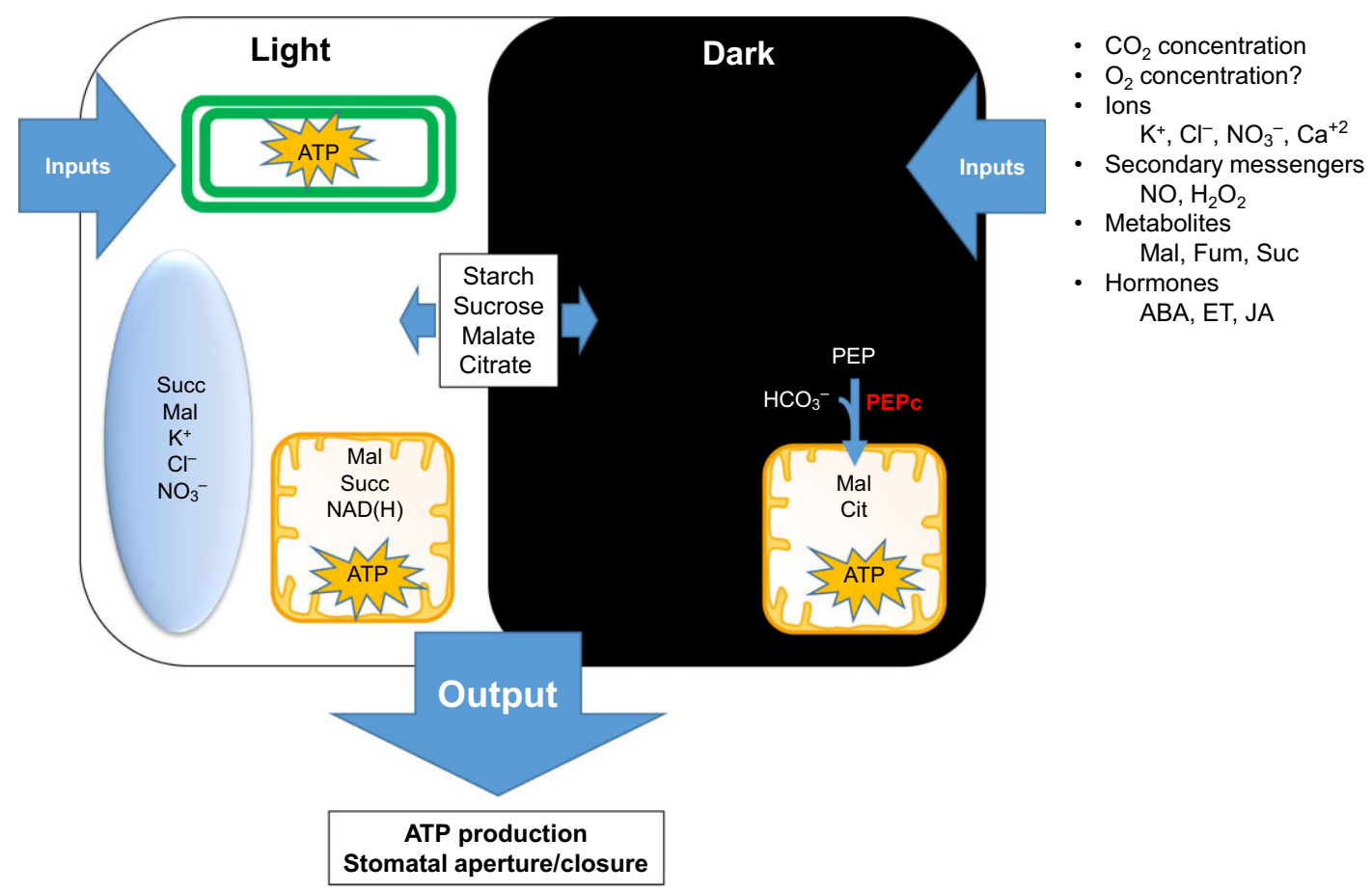

Figure 2. The main regulators of guard cell movements. Schematic representation of guard cell metabolism of C3 plants in both light and dark phases. For guard cell modelling it is important to consider the particularities of guard cell metabolism, which are represented in the figure by the number of possible inputs (environment signals, ions, secondary messengers, metabolites, hormones) and the high compartmentalization of the metabolism, which involves transport and accumulation of ions and metabolites in the apoplast and organelles (plastids, mitochondria and vacuole). It is also important to consider that guard cells have a metabolism similar to C4 plants and not $\mathrm{C} 3$ plants, represented in the figure through the activity of the enzyme phosphoenolpyruvate carboxylase (PEPc) in the dark phase. Beyond ATP production, which is commonly used as output, guard cells have a specific output that has substantial physiological importance - stomatal aperture or closure. Abbreviations: ABA, abscisic acid; $\mathrm{Ca}^{+2}$, calcium; $\mathrm{Cl}^{-}$, chloride; Cit, Citrate; $\mathrm{CO}_{2}$, Carbon dioxide; ET, ethylen, Fum, fumarate; $\mathrm{HCO}_{3}{ }^{-}$, Bicarbonate; $\mathrm{H}_{2} \mathrm{O}_{2}$, hydrogen peroxide; JA, jasmonic acid; $\mathrm{K}^{+}$, potassium; Mal, malate; $\mathrm{NO}_{3}{ }^{-}$, nitrate; $\mathrm{NO}$, nitric oxide; $\mathrm{O}_{2}$, Oxygen; Succ, Succinate.

movement depends on many exogenous variables (Fig. 2) that affect the internal networks on multiple levels of cellular organization ranging from aspects of transcriptional regulatory networks, signalling and metabolism. For this reason, system perturbation by the application of a series of independent environmental cues (or their combinations), would make it increasingly difficult to distinguish between their primary and secondary effects. This complexity is further exacerbated in instances wherein these stress perturbations are not simply applied to wild-type tissues, but also to genetic variants such as mutants or transgenic lines. Moreover, the differential coverage of cellular components by high-throughput technologies currently renders data interpretation rather difficult (Fernie \& Stitt 2012). It should be mentioned that these incoherencies are not only due to technical issues, but also related to the complexity and structure of metabolic networks (Araújo et al. 2012).

To this end, data-driven integrative modelling will likely prove highly useful for both in silico investigation of the effects of environmental changes and reverse engineering of the networks underlying guard cell functions. Moreover, using the outcome of the system-level simulations to plan validation experiments will be highly instructive and will likely result in several iterative cycles of experimentation and modelling. Such an approach may alleviate some of the problems encountered by guard cell experimentalists most acutely perhaps is reducing the number of experiments needed, which given that difficulties in obtaining the required number of guard cells often represents the bottleneck in the experimental studies of guard cells.

Finally, the ultimate goal of the systems biology approach is to understand the system with the aim of manipulating its function towards a desired outcome. Therefore, systems approach, carefully integrating high-throughput data with (possibly) large-scale models of metabolism and regulation/ signalling can further contribute to identifying novel determinants on a molecular level as well as to plan intervention strategies (discussed in detail later in the section 'Opportunities and challenges in systems modelling of stomatal function').

\section{Application of systems biology approaches to stomata}

The differential analysis of multiple cell types and organs is one approach to dissect regulatory signalling networks and metabolic pathways underlying complex molecular functions, and has been deemed crucial for the development of systems 
biology (Ideker \& Krogan 2012). Such comparative analyses require the use of high-throughput phenotyping technologies that permit the generation of large volumes of data. These data can, in turn, be used to either generate or test hypotheses with respect to the genes and their products (i.e. proteins) as well as to downstream metabolites, which exhibit differential behaviour across tissues or cells under different environmental conditions. A major bottleneck and challenge in plant cell-specific studies, however, is in obtaining different cell types in high enough quantity and quality for downstream analysis (Misra et al. 2014). Nevertheless, several elegant studies involving the parallel usage of different highthroughput technologies have employed guard cells. Most of these studies, mainly performed in Arabidopsis, focused on the identification of molecular components of the ABA signal cascade. We highlight these studies and the knowledge advances, which they provided in the first part of this paper and subsequently offer a perspective on the modelling of guard cell function. Finally, we will present what in our opinion are the major outstanding questions in understanding guard cell function.

\section{Transcriptomics studies}

As a first step towards a deeper understanding of guard cell functioning, we provide a summary of publicly available transcriptomic data from guard cell studies. It is important to mention that most of studies available to date have been used to analyse the response to ABA and the ABA signalling pathway. Accordingly, most of the data available was generated in Arabidopsis mutant plants (Table 1). Given that the response of plants to environmental cues, particularly stresses, often involves the coordinated induction or repression of gene expression, transcriptomics studies provide investigation of one critical facet of the molecular response of guard cells.

Oligomer-based DNA microarray was used in earlier studies to profile gene expression in Arabidopsis guard cells, facilitating the identification of $\sim 1300$ genes, which were expressed in guard cells (Leonhardt et al. 2004). On comparison of guard cell expression profiles with those from mesophyll cells, 64 transcripts were identified to be preferentially expressed in guard cells. Importantly, the reliability of this approach was further confirmed by quantitative RT-PCR. Analysis of the expression profile of guard cells had additionally revealed the ABA-responsive genes that govern the behaviour of guard cell ABA-signalling components (Leonhardt et al. 2004).

In a more recent study, guard cell transcriptome data were used to identify novel modes of (heterotrimeric) G-proteins action (Pandey et al. 2010). G-proteins comprise three subunits, alpha $(\mathrm{G} \alpha)$, beta $(\mathrm{G} \beta)$ and gamma $(\mathrm{G} \gamma)$, and are important transmembrane components of signal transduction (Temple \& Jones 2007; Kumar et al. 2014). Given that G-proteins can mediate a wide range of essential signalling pathways in eukaryotes this protein family might be involved in aspects of guard cell signalling (see discussion on 'Proteomics studies' later). By analysing microarray data from guard cells and excised leaves of G-protein subunit mutants of Arabidopsis, with and without ABA treatment, the classical mechanisms of G-protein signalling was confirmed and a novel route of G-protein signalling, in which $\mathrm{G} \beta$ subunit regulates gene expression independently of $\mathrm{G} \alpha$ subunit, was discovered. Notably, it was also observed that G-protein mode of transcriptional regulation differs between guard cells and leaves, supporting a systemspecificity of G-protein signalling. These observations clearly improve resolution of the molecular network of ABA-responsive genes and could plausibly be used as new inputs in modelling approaches that predict stomatal movements in addition to those involving solute transport across membranes.

Another recent study involving ABA regulation of gene expression in guard cells have identified a unique cis-acting motif, GTCGG, associated with ABA-induction of gene expression specifically in guard cells (Wang et al. 2011). In addition, approximately 300 genes displaying ABA-specific regulation were uncovered in guard cells, including genes known to encode ion transporters associated with stomatal opening (e.g. the $\mathrm{H}^{+}$-ATPase OPEN STOMATA 2 OST2, the POTASSIUM CHANNEL IN ARABIDOPSIS THALIANA 1 and $2-K A T 1$ and KAT2, the SUGAR TRANSPORTER $1-S T P 1$, the endosomal $\mathrm{Na}^{+} / \mathrm{H}^{+}$antiporter CATION/H + EXCHANGER 20-CHX20, and the NITRATE TRANSPORTER 1 - NRT1). These genes were down-regulated upon ABA treatment, suggesting that this regulation may be an important aspect of mid- to long-term inhibition of stomatal opening by ABA as well as ensuring the maintenance of stomatal closure during stress situations such as drought. Moreover, these results provided evidence for cross-talk at the transcriptional level between ABA and another hormonal inhibitor of stomatal opening, namely, jasmonate (Wang et al. 2011).

Microarray analysis was additionally performed on guard cells from leaves of Arabidopsis treated with sucrose to test the hypothesis that photosynthesis-derived sugar acts as a signal in guard cells, which allows adjustment of their stomatal opening (Bates et al. 2012). This study revealed that the expression of 440 genes changed in response to sucrose in guard cells including genes involved in several important cellular functions such as photosynthesis and transport of sugars, water, amino acids and ions. Remarkably, investigation of T-DNA insertion lines for 50 genes highly responsive to sucrose revealed that 12 genes, which were not previously known to function in guard cells, are important in leaf conductance control, water-use efficiency and/or stomata development. Of these, three are of particular interest given that they showed similar effects in nearly all test of stomatal function without a change in stomatal density: a trehalose phosphate synthase TPS5 (At4g17770), a TRAF domain-containing protein (At1g65370), and a WD repeat-containing protein (At1g15440) (Bates et al. 2012). Collectively, these results demonstrate the power of largescale gene expression studies as an effective tool in revealing candidate genes with potential for practical application in field-related experiments. 


\section{ABA - Induced}

\section{A (1170)}

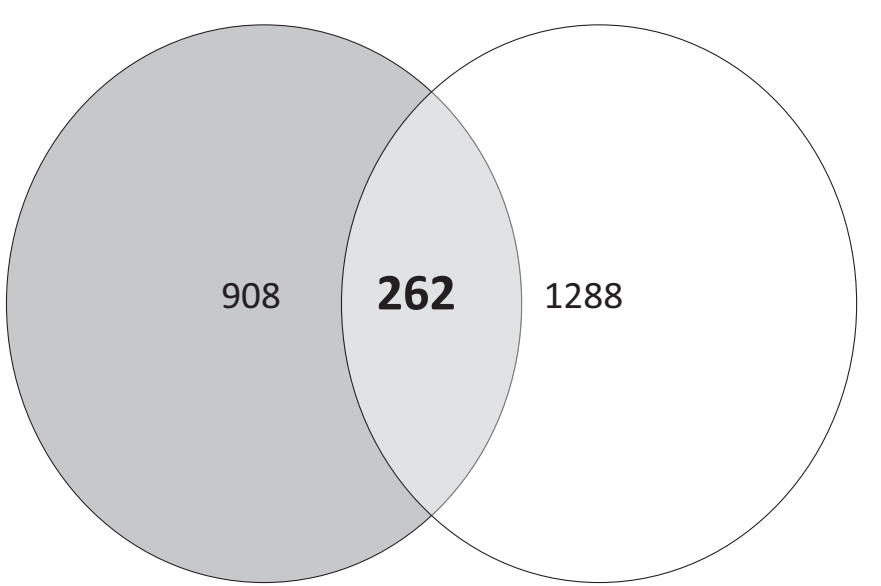

A (202)

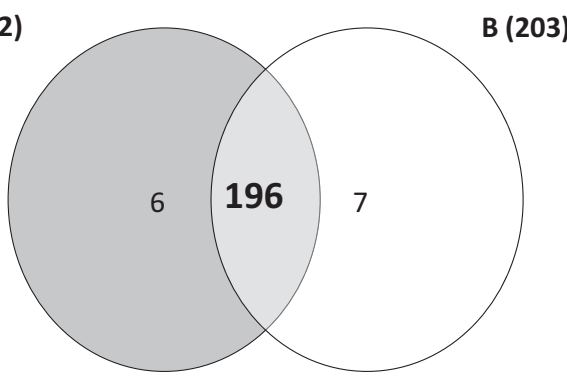

ABA - Repressed

$A(60)$

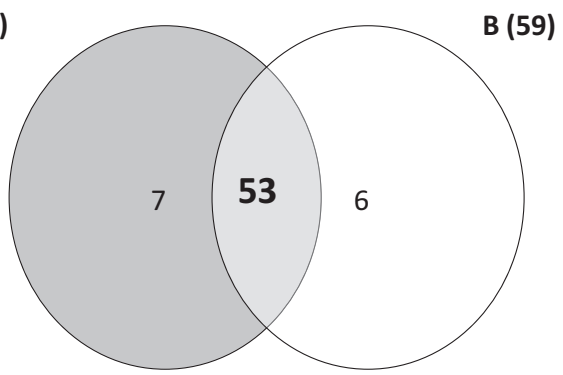

Figure 3. Venn diagram showing the transcriptome overlap of studies on ABA response in guard cells. (a) and (b) correspond to Wang et al. (2011) and Bauer et al. (2013), respectively. Notably, we found 262 genes that were responsive to ABA treatment in both studies. Additionally, we overlapped the genes that were ABA-induced (196) or repressed (53) from the list of the 262 genes previously found. The data used are available in the Supporting Information Table S1. The Venn diagram was constructed in the Pangloss Venn diagram generator (http://www.pangloss.com/seidel/Protocols/venn4.cgi).

In a similar approach, the expression profiles of Arabidopsis plants under dry air conditions, characterized by long-term stomatal closure, revealed 588 differentially regulated genes (Bauer et al. 2013). Given that transport is an essential activity of guard cells, it is not surprising that genes associated with this function were found to be highly expressed in guard cells (e.g. KAT1, KAT2, GATED OUTWARDLY-RECTIFYING $K^{+}$CHANNEL - GORK, SLOW ANION CHANNEL-ASSOCIATED 1 - SLAC1, SLAC1 HOMOLOGUE 3 - SLAH3, and QUICKACTIVATING ANION CHANNEL 1-QUAC1). It is worth mentioning that when treated with exogenous ABA, 1550 genes were sensitive to ABA of which 1080 were up-regulated and 470 were down-regulated (Bauer et al. 2013).

Most recently, Negi and collaborators isolated an Arabidopsis mutant, stomatal carpenter 1 (scap1) that develops irregularly shaped guard cells lacking normal stomatal function, and showing defects in $\mathrm{CO}_{2}$-induced stomatal closing and light-induced stomatal opening from an M2 population of ethyl methanesulfonate (EMS)-mutagenized Arabidopsis plants (Negi et al. 2013). SCAP1 was identified to encode a plant-specific DNA binding with one finger (Dof) transcription factor, and its role in guard cell gene expression was investigated by microarray experiments.
These experiments identified 1540 genes that are expressed in guard cells, but not in mesophyll cells. The scap1 mutation resulted in decreased expression of genes for several factors directly involved in stomatal opening and closure, namely, GORK (Hosy et al. 2003), PYL2, a regulatory component of ABA receptor 2 (Park et al. 2009) and MYB60, an essential transcriptional regulator for guard cell movements (Cominelli et al. 2005). Thus, SCAP1 regulates not only stomatal guard cell maturation, but also stomatal functions through its direct involvement in the final stages of guard cell differentiation.

By focusing on well-known ABA-responsive genes, we here utilize a Venn diagram to visualize the overlap of the findings from these most recent guard cell studies employing transcriptome analyses (Wang et al. 2011; Bauer et al. 2013). Notably, we found 262 genes that are responsive to ABA treatment in both experiments (Fig. 3 and Supporting Information Table S1). These genes could thus be strong candidates for being involved in the functional response to changes in ABA levels as well as representing potential targets for future experimental work to further dissect the ABA-response network.

Notably, transcriptomes as assessed by microarrays have produced an unprecedented amount of data regarding transcript identity and levels in plant systems and also in guard 
cells network and cascades that have been elegantly elucidated. Additionally, although next-generation DNA sequencing technologies are driving increasingly rapid, affordable and high resolution analyses of plant transcriptomes through sequencing of their associated cDNA (complementary DNA) populations; an analytical platform commonly referred to as RNA-sequencing (RNA-seq) (Martin et al. 2013), not so much has been performed in guard cells thus far. Remarkably RNA-sequencing is currently wellestablished as a versatile platform with applications in an ever-growing number of fields of plant biology research, including naturally guard cell studies. Collectively, there is plenty of reason to believe that guard cell microarrays and transcriptome sequences can provide a valuable resource for plant breeding and research helping in the identification of novel insights into common plant responses to several environmental stress and offer candidate genes or markers that can be used to guide future efforts attempting to breed tolerant plants.

\section{Proteomics studies}

Proteomics analyses complement transcriptomics-based studies and can provide better understanding of the interplay between cellular levels since proteins are generally functionally involved either in regulatory, signalling or metabolic processes. At the proteomic level, comparative analysis of purified guard cells and mesophyll cells from Brassica napus has first been performed using the isobaric tags for relative and absolute quantification (iTRAQ) technology alongside two-dimensional (2D) liquid chromatography mass spectrometry (Zhu et al. 2009). This strategy identified around 1450 non-redundant proteins in both guard cells and mesophyll cells. Interestingly, 427 of these proteins were quantified, and 74 of them were found to be enriched in guard cells. As would perhaps be anticipated, proteins involved in energy metabolism, transport, transcription, cell structure, and signalling were preferentially expressed in guard cells, providing further support to the idea that guard cells can, at least partially, function autonomously (Schroeder et al. 2001; Hashimoto et al. 2006; Young et al. 2006; Sirichandra et al. 2009).

In another study related to ABA signalling and stomatal movement, more than 1700 unique proteins from Arabidopsis guard cell protoplasts were identified using three complementary proteomic methods (Zhao et al. 2008). This extensive single-cell proteomics approach identified not only proteins whose encoding genes were not previously identified in transcriptome analyses of guard cells, but also signalling proteins, of which two were suggested to be related to guard cell function. For instance, THIOGLUCOSIDE GLUCOHYDROLASE1 (TGG1), a myrosinase, catalyses the production of toxic isothiocyanates from glucosinolates. This protein was more abundant in the guard cell proteome, and the tgg1 mutants were hyposensitive to ABA inhibition of guard cell inward $\mathrm{K}^{+}$channels and stomatal opening. As such, this study revealed that the glucosinolate-myrosinase system, previously identified as a defense against biotic invaders, is also required for key ABA responses of guard cells of Arabidopsis (Zhao et al. 2008). That said it is important to note that glucosinolates are mainly present in the family Brassicaceae (Fahey et al. 2001), and as such this is very much a specialized rather than a general mechanism of guard cell regulation.

A further component of the Arabidopsis ABA-responsive network underpinning stomatal movement was also identified by using iTRAQ technology. In this study guard cell proteins whose abundance was affected by ABA supply and/or mutation in G PROTEIN ALPHA SUBUNIT 1 (GPA1) in Arabidopsis thaliana were investigated. Accordingly, this elegant study has demonstrated that the G-protein $\alpha$ subunit, GPA1, is implicated in ABA-regulated guard cell movement, confirming thus a previous transcriptome analysis (Pandey et al. 2010). It is worthy to mention that the abundance of two proteins in Col-0 and six proteins in gpal-4, a null mutant lacking the G $\alpha$ subunit, was affected by ABA treatment in guard cells, whereas 18 guard cell proteins were quantitatively affected by mutation in GPA1. Remarkably, these are proteins clearly involved in photosynthesis as they participate in the Calvin-Benson cycle, photosynthetic light reactions, ATP synthases and chloroplastic electron transfer. It is also worth mentioning that a further five proteins whose abundance increased in gpal-4 guard cells are members of the so-called 'response to stress' family including proteins involved in oxidative stress (Zhao et al. 2010). Altogether, the results of these studies indicated that GPA1 not only inhibits guard cell photosynthesis, but also promotes the availability of reactive oxygen species (ROS) in guard cells.

Analysis of ABA responsive proteins in B. napus guard cells has also been performed, with a total of 431 unique proteins being unequivocally identified, of which 66 increased and 38 decreased (Zhu et al. 2010). The proteins that were more highly abundant following ABA treatment included proteins involved in stress and defence while proteins with functions in spermidine synthesis, rhamnose biosynthesis, jasmonic acid biosynthesis, fatty acid betaoxidation, purine metabolism, alkaloid biosynthesis and protein synthesis decreased. Surprisingly, some of the metabolic pathways that were suppressed are additionally important in plant stress and defence (Zhu et al. 2010). Furthermore, given that many of these proteins have not previously been reported as either being ABA responsive or being involved in stomatal movement, it suggests that further novel players involved in guard cell ABA signalling may yet remain to be identified.

At a more mechanistic level, a recent phosphoproteomic approach identified proteins that were phosphorylated following ABA treatment or under dehydration stress in Arabidopsis wild-type plants, but not in mutants lacking all three kinases of the SUCROSE NON FERMENTING 1 (SNF1)-RELATED PROTEIN KINASE 2s (SnRK2s) family (Umezawa et al. 2013), which are central components of ABA signalling pathways. The number of differentially phosphorylated peptides was greater in srk2dei plants treated with ABA than in the ones subjected to dehydration, suggesting that SnRK2 was mainly involved in ABA signal- 
ling rather than dehydration. SnRK2 also promotes the ABA-induced activation of the Mitogen-activated protein kinases (MAPKs) AtMPK1 and AtMPK2, AREB1 (ABAresponsive element binding protein 1), and stimulate ABA-responsive gene expression. Furthermore, SnRK2SUBSTRATE 1 (SNS1), a previously unknown protein, was phosphorylated in vivo following isolation and functional characterization of knockout mutants of SNS1 it was revealed that SNS1 is a negative regulator of ABA signalling at the post-germination stage in Arabidopsis.

As discussed earlier, proteomic approaches have recently expanded our view of the protein landscape required for and during stomatal movements and thus contributed significantly in advancing our mechanistic understanding of ABA signalling controlling guard cell movements. However, there are still large gaps in the knowledge concerning the changes of the proteome during adaptation to environmental stress conditions that lead to changes in stomatal aperture. With the application of proteomic methods, particularly 2D-gel and gel-free, LC/MS-based methods, insights into the composition and dynamic changes of the guard cell proteome could be obtained. It is reasonable to assume that a thorough understanding of guard cell response to abiotic stress at the molecular level is a prerequisite for its effective management. Notwithstanding, the molecular mechanism involved in guard cell movements is seemingly complex and requires information at the post-genomic level to understand it effectively. In this regard, the ever-growing field of proteomics is also being effectively employed for investigating guard cell responses in land plants. The development of proteomics techniques allowing increased proteome coverage and quantitative measurements of proteins will be particularly instrumental to characterize proteomes and their modulation during guard cell movements. Despite important advances, plant proteome analysis, including those of model plant species, remain constrained by limitations inherent to proteomics techniques and data interpretation. Here we have, accordingly, highlighted the prominent approaches and achievements of proteomics with model plant Arabidopsis and have not discussed the current limitations of plant proteomics, which has been expertly reviewed elsewhere (Lilley \& Dupree 2007; Abril et al. 2011; Nakagami et al. 2012; Vanderschuren et al. 2013). We anticipate future directions that could advance the contribution of plant proteomics to crop improvement and additionally indicates that proteomic approaches could generate a huge amount of data, and therefore adequate advancements in computational and mathematical tools are a must to be achieved for effective analysis. It is important to note, however, that the integration of genomic-scale information to address complex genetics and physiological questions still remains challenging.

\section{Metabolomics studies}

Last, but by no means not least, it is plausible that metabolomics of guard cells will ultimately become a highly powerful approach in dissecting the functioning of guard cells. Although no single analytical system is ever likely to cover the whole metabolome technological developments have considerably extended our ability to analyse complex biological systems, facilitating the simultaneous detection of different compound classes with diverse chemical properties (Osorio et al. 2012). Notably, the development of new technologies might ameliorate the problem of limited metabolite coverage. It is important to mention, however, that given the level of physical and chemical complexity of properties of metabolites coupled with other factors, such as the dynamic measurement range that is required, make the development of a single analytical platform that will provide a comprehensive analysis of the cellular metabolome a formidable challenge (Fernie et al. 2004; Misra et al. 2014), rendering metabolomics more complicated than other post-genomic analysis. To date, metabolomic analyses in guard cells are still incipient compared with transcriptomic and proteomic. Although the focus of metabolomics has largely been to elucidate the flow of mass in the substrate-product conversions, metabolomics may also be used as a tool for the elucidation of the information flow in cellular signalling networks, as we illustrate later.

Using liquid chromatography-multiple reaction monitoring mass spectrometry for targeted analysis of 85 signallingrelated metabolites in Arabidopsis guard cell protoplasts over a time course of ABA treatment, it was possible to dissect signalling aspects of the guard cell in response to ABA (Jin et al. 2013). For this purpose, Arabidopsis wild-type plants (Col-0) and gpal mutants, which have ABAhyposensitive stomata (Zhao et al. 2010), were evaluated. The metabolomes of these plants revealed coordinated regulation of signalling metabolites in unrelated biochemical pathways. Interestingly, hormone metabolites were responsive to $\mathrm{ABA}$, with generally greater responsiveness in Col-0 than in gpal. Thus, for instance, indole-3-acetic acid (IAA) levels were decreased by ABA in wild-type guard cells, but not in gpal guard cells. Additionally, the majority of hormones also displayed different ABA responses in guard cell metabolite profiles when compared with the one observed in mesophyll cell metabolomes, suggesting that ABA is most likely an upstream actor to regulate other hormones (Jin et al. 2013).

Indeed, it seems clear that hormones are good targets to investigate guard cell metabolomics and although great attention has been paid to ABA, there is a crosstalk between ABA and other hormones that can also affect stomatal movements. For instance, brassinosteroid and jasmonate can act concurrently with ABA promoting senescence and programmed cell death (Zhang et al. 2009; Hossain et al. 2011). On the other hand, other hormones such as cytokinin, auxin, salicylic acid and ethylene can act antagonistically to ABA in response to water deficit (Tanaka et al. 2005; Pinheiro \& Chaves 2011; Ha et al. 2012; Chen et al. 2013; Meguro \& Sato 2014).

The increased photosynthesis and whole-plant biomass observed in tomato plants where antisense inhibition of the iron-sulphur subunit of the succinate dehydrogenase (SDH) was performed seems to be related to an organic acidmediated effect on stomatal aperture (Araújo et al. 2011c). These results are diametrically opposite to those obtained for 
antisense inhibition of fumarase, where decreased photosynthesis and biomass were observed (Nunes-Nesi et al. 2007). Furthermore, measurement of apoplastic organic acid levels in SDH and fumarase antisense plants, revealed a negative correlation between the levels of fumarate and stomatal conductance, although the influence of fumarate appears to be weaker than that of malate (Araújo et al. 2011c). It is highly interesting that similar results were obtained by inhibiting two different complex II subunits, the iron-sulphur subunit in tomato (Araújo et al. 2011c) and the flavoprotein in Arabidopsis (Fuentes et al. 2011). Taken together, the results of these work provided compelling evidence to support that modulation of malate and fumarate concentration can strongly impact stomatal movements. Perhaps more importantly, these results also provide strong support of the theory that guard cells are not autonomously regulated (Mott 2009) and that the mesophyll harbours significant control over guard cell movements (Lee et al. 2008b; Fernie \& Martinoia 2009; Mott 2009; Araújo et al. 2011b). Collectively, these results also indicate that mesophyll-derived signals (e.g. malate and fumarate), which play an important role in regulating stomatal movements (Hedrich et al. 1994; Araújo et al. 2011c), may be candidate signalling molecules. Importantly, further identification of mesophyll-derived signal molecules will provide essential information about $\mathrm{CO}_{2}$-signalling mechanisms including guard cell receptors that sense $\mathrm{CO}_{2}$ signals from the mesophyll. In summary, metabolite profiling has aided in the identification of novel interactions between the tricarboxylic acid (TCA) cycle and photosynthesis and stomatal function. Nevertheless, the metabolic and molecular regulatory hierarchy underlying this highly specialized cell type is as yet not fully understood and therefore further work is clearly required in order to establish the regulatory mechanisms involved in such responses.

Overall, while post-genomic technologies have already aided our understanding of guard cell metabolism at a systems level through additions to the 'parts list' of the metabolic network, they are poised to become more useful still through the discovery of new interactions and the provision of the quantitative data required for the construction of predictive models of metabolism. It should be mentioned that, alongside other studies, metabolic studies of this highly specialized cell type has demonstrate to be useful in increasing our understanding of the hormonal crosstalk and metabolic regulation of stomatal movement that is important for plant growth, development, yield and response to environmental factors. It is no doubt that the further development and combination of many analytical techniques (Fig. 1) will additionally allow a fuller description of the metabolic network in a guard cell context.

\section{Opportunities and challenges in systems modelling of stomatal function}

Classical modelling approaches focus on expressing the stomatal conductance $\left(g_{\mathrm{s}}\right)$ as a function of other external and internal factors. The goal of this section is not to offer an overview of the existing modelling approaches; the reader is instructed to consult previous comprehensive reviews (Damour et al. 2010; Buckley \& Mott 2013). These reviews have already categorized the existing models into three groups, largely based on the methodology used for their establishment, namely: purely data-based (e.g. developed by the boundary-line method; Jarvis 1976), mechanistic (e.g. based on the consideration of hydraulic properties and biophysical properties of guard cells) (Cowan 1972), and optimization-based (i.e. based on the idea that plants use the limiting resources in the most optimal way towards fulfilling a task) (Cowan \& Farquhar 1977).

The above mentioned experimental evidence has clearly indicated that understanding of stomatal function has to directly consider the gradient in spatio-temporal scales, starting from modelling of single guard cell over fast changes in environmental determinants to theoretical investigations of the interactions between guard and mesophyll cells via various feedback loops and their coupling to data read-out to modelling of canopy over developmental and environmental gradients. The particular modelling question would determine the type of modelling strategy that has to be used; for instance, dynamic changes of well-characterized (sub)systems over short time intervals can be readily undertaken through kinetic modelling, whereas analysis of typical longterm or steady-state behaviour as well as integration of data from multiple cellular components is more readily tackled by means of large-scale stoichiometric models which often do not require kinetic parameterization (see following paragraphs for detailed discussion). The vast time scales of cellular processes that occur at different levels of cellular organization, ranging from metabolism (as fast) to protein synthesis and gene regulation (as slower) will also delineate the applicability of quasy-steady-state assumption as well as the lumping of various components as it is usually performed in modelling studies (Famili \& Palsson 2003; Jamshidi \& Palsson 2008).

The existing model categories and their combinations have clearly contributed to the predictive modelling and refinement of the relationship between $g_{\mathrm{s}}$ and its determinants. They have, however, had limited success in illuminating how the changes in stomatal movement, and through it $g_{\mathrm{s}}$, are affected by the interplay of the environment, the various cellular organizational levels (e.g. transcripts, proteins, and metabolites), and the coordination between different cell types (e.g. guard and mesophyll cells). Therefore, despite efforts made to link environmental and endogenous factors to stomatal movements in mathematical models, these modelling approaches have not been used to determine wellplanned in silico genetic manipulation strategies to investigate means by which to alter conductance-dependent traits and do not integrate data from multiple environments with the purpose of more accurate parameterization. Furthermore, these modelling approaches need to be continuously improved and augmented by inspecting not only the fit of the model predictions under various environmental factors but also from genetic manipulation strategies altering conductance-dependent traits. In fact, our current view is that 
to develop an integrated understanding of stomatal function, the modelling approaches must couple the several processes across all levels of stomatal movements. Accordingly, it seems reasonable to assume that a single model of stomatal function must encompass all of those surrounding processes, including naturally the interactions between guard cells and surrounding tissues and their coupling with the environment (Lawson \& Blatt 2014). Finally, the importance of these models will become prominent due to their ultimate test from investigating and validating genetic manipulation strategies from seemingly unrelated aspects of cellular subsystems, from metabolism down to gene regulation.

These challenges could, in part, be addressed by kinetic stomatal models of smaller scale, for which the kinetic form of the reaction rates (e.g. Michaelis-Menten) together with its numerous parameters, may be more facile to obtain. The sole prominent example of this direction is the kinetic-based modelling approach proposed initially (Hills et al. 2012) and more thoroughly validated later (Chen et al. 2012; Wang et al. 2012; Blatt et al. 2013). This kinetic model is implemented within the OnGuard software package (Available at http:// psrg.org.uk/guard-cell-modelling/), a computational platform incorporating properties of transporters at the plasma membrane and tonoplast, features of osmolite metabolism, as well as the characteristics such as the cytosolic $\mathrm{pH}$ and $\mathrm{Ca}^{2+}$ buffering capacity (Lawson \& Blatt 2014). We would like to point out that the current implementation includes data-driven parameterization of the model as well as investigation of the effects of parameter changes on the quantitative predictions. Thus, the existing in silico studies based on OnGuard have demonstrated the capacity of this framework to provide a multitude of quantitative predictions which can now readily be used for goodness-of-fit testing with data from independent experiments and for improved calibration of the model. While the currently implemented model has aided the quantitative understanding of stomata behaviour as a function of few metabolic reactions, related to proxies for osmolites, transport and signalling, its role in design of metabolic engineering strategies, because of the number of considered genes, enzymes and metabolites, remains to be experimentally demonstrated. Therefore, cell-specific manipulation of metabolic pathways and their effects on stomatal functions seem challenging to investigate in the framework of OnGuard.

Genome-scale metabolic modelling offers the opportunity to overcome the aforementioned problems of the existing modelling approaches. This is due to the fact that genomescale metabolic models consider the entirety of the characterized biochemical reactions in a particular organism (Bordbar et al. 2014). Therefore, they readily facilitate a direct in silico inspection of the effects of environmental changes or reaction manipulations (e.g. knock-out mutants, silencing of expression or overexpression strategies) (Lewis et al. 2012) on particular composite traits such as biomass or reaction fluxes. Moreover, methodological advances have allowed direct integration of transcriptomics and proteomics datasets resulting in more physiologically relevant predictions of metabolic states of specific cell types under different conditions (Sweetlove \& Ratcliffe 2011; Töpfer et al. 2013, 2014). Most importantly, recent studies have focused on using the data generated by these high-throughput technologies to arrive at context-specific metabolic networks, where a context stands either for a particular genotype, organ and cell type (e.g. guard cell), or for different environmental conditions (Estévez \& Nikoloski 2014). Such models will have to be general enough to simulate different environments, which challenges the usage of condition-independent biomass reaction (Feist \& Palsson 2010) (see critique in Töpfer et al. 2013 for plants) or different tasks such as ATP production (Fig. 2) usually assumed to be optimized for modelling using flux balance analysis (FBA) (Boyle et al. 2009; Raman \& Chandra 2009), which is reasonable to apply for guard cell modelling given the importance of the ATP turnover in guard cells (Suetsugu et al. 2014; Wang et al. 2014a,b).

In parallel with modelling advances for $\mathrm{C} 3$ model plants, Arabidopsis, (de Oliveira Dal'Molin et al. 2010a; Arnold \& Nikoloski 2013, 2014; and references therein), there have been developments and refinement of genome-scale metabolic models for $\mathrm{C} 4$ model plants (e.g. maize). The latter are more involved as they capture the interplay between two cell types, bundle sheath and mesophyll, via transport of different metabolites through the plasmodesmata (de Oliveira Dal'Molin et al. 2010b; Saha et al. 2011; Simons et al. 2014). Therefore, they can provide the impetus for modelling the communication between guard and mesophyll cells to simulate leaf growth. Such an approach would also provide the necessary comparison between $\mathrm{C} 3$ and $\mathrm{C} 4$ species with respect to the behaviour of such multicellular systems in terms of different properties, including efficiency of resource usage and patterns of (re)allocation upon different changes, giving this line of research an evolutionary perspective (Mallmann et al. 2014).

However, this approach also has numerous challenges because of the nature of the model and the type of reactions considered. First, as prominent constraint-based methods to analyse genome-scale models, FBA and its derivatives largely assume steady-state behaviour, although stomatal movement is a dynamic process. Therefore, it is necessary to develop novel methods to allow investigations of dynamical aspects of large-scale models, particularly as the existing solutions, such as dynamic FBA, can only be applied to models of small to moderate size because of the large computational demands of the employ formulation (Kleessen \& Nikoloski 2012; Kleessen et al. 2012). Second, these genome-scale metabolic models mostly neglect regulatory and signalling cascade, which can modulate the behaviour of metabolism, although recent method developments have rendered the integration of transcriptional regulatory cascades possible in Escherichia coli and Micobacterium tuberculosis (Chandrasekaran \& Price 2010,2013) and signalling cascades in a small network for Saccharomyces cerevisiae (Lee et al. 2008a). Moreover, as the behaviour of signalling pathways usually depends on the concentration of the ligand (e.g. metabolite, which modulates the transduction of the signal to the other cellular levels), the genome-scale models will have 
to move from flux-centric to concentration-centric in order to allow the association of flux distributions with the concentrations of the considered metabolites (Töpfer et al. 2015). Resolving these challenges in parallel with the development of large-scale models of guard cell metabolism will most likely pave the way for truly predictive modelling (and validation), which will certainly have far-reaching applications.

Finally, aside from the issues related to simulation of the dynamics process, one has to consider the effect of spatial scales. To this end, the existing models of $g_{\mathrm{s}}$ for single leaves have been scaled up to the level of canopy, often performed following the big-leaf top-down approach (Baldocchi et al. 1991). To this end, there is the alternative of determining the canopy $g_{\mathrm{s}}$ as the sum of the conductance of individual leaves (see Blonquist et al. 2009) or following the Penman-Monteith equation (Monteith 1981; Furon et al. 2007). The former could be used to combine multiple large-scale models of illuminated and shaded leaves, with the idea of expanding the applicability of the large-scale models on the level of canopy, a much desired extension of the applicability of constraint-based approaches.

\section{CONCLUDING REMARKS}

Prompted by the discovery that genetic manipulation of guard cells is a promising strategy to improve plant growth, water-use efficiency and drought tolerance (Lebaudy et al. 2008; Antunes et al. 2012; De Angeli et al. 2013; Schroeder et al. 2013; Wang et al. 2014b), recent years have seen the accumulation of experimental evidence concerning different aspects of stomatal behaviour. This is largely due to elegant studies of molecular physiology of guard cells based on application of high-throughput technologies ranging from transcriptomics and proteomics to metabolomics. Our opinion is that the gathered large-scale datasets provide the basis for the creation of dynamic genome-scale metabolic models of guard cells. We posit that their coupling to models of other cell types will allow us to predict targets for genetic manipulation to improve crop yield, particularly under suboptimal conditions.

Given the complexity of the interconnected networks governing stomatal movements under extremely variable internal and external conditions, we argue that a systems approach, which simultaneously uses different highthroughput technologies to gather data and then integrates them within large-scale models of regulation, signalling and metabolism is a viable strategy towards the rational design of intervention strategies. Such an approach is greatly facilitated by recent advances in context-specific models of plant metabolism and methods for integration of metabolomics data in flux-oriented approaches.

The grand challenge for this research field is to gain a fuller understanding as to how the regulation of stomatal movement occurs and how it may have evolved because of the interplay between genotypes and changing environ- ments. Use of mathematical approaches to enhance our understanding of the interaction of the various molecular components of the cell (and their dynamic changes underlying this process) and how they are adjusted following environmental changes, can be evaluated in large-scale models in a relatively facile manner. While we are aware that achieving this goal is a vastly challenging task for any cell type we feel that the accessibility of guard cells and the relatively easy enrichment procedures involved in their isolation render them a valuable cell type not only for investigating this specific interaction between a plant cell and its environment as well as between different tightly coupled cell types, but also for looking at the specialization of plant cell function in general.

\section{ACKNOWLEDGMENTS}

This work was supported by funding from the Max Planck Society (to A.R.F., Z.N., W.L.A.) and the National Council for Scientific and Technological Development (CNPq-Brazil, Grant 483525/2012-0 to W.L.A.). Scholarships granted by CNPq-Brazil and FAPEMIG to D.B.M. and D.M.D., and research fellowships granted by $\mathrm{CNPq}$-Brazil to W.L.A. are also gratefully acknowledged.

Conflicts of Interest: The authors declare that the research was conducted in the absence of any commercial or financial relationships that could be construed as a potential conflict of interest.

\section{REFERENCES}

Abril N., Gion J.-M., Kerner R., Müller-Starck G., Cerrillo R.M.N., Plomion C., .. Jorrin-Novo J.V. (2011) Proteomics research on forest trees, the most recalcitrant and orphan plant species. Phytochemistry 72, 1219-1242.

Antunes W.C., Provart N.J., Williams T.C.R. \& Loureiro M.E. (2012) Changes in stomatal function and water use efficiency in potato plants with altered sucrolytic activity. Plant, Cell \& Environment 35, 747-759.

Araújo W.L., Fernie A.R. \& Nunes-Nesi A. (2011a) Control of stomatal aperture: a renaissance of the old guard. Plant Signaling \& Behavior 6, 13051311.

Araújo W.L., Nunes-Nesi A. \& Fernie A.R. (2011b) Fumarate: multiple functions of a simple metabolite. Phytochemistry 72, 838-843.

Araújo W.L., Nunes-Nesi A., Osorio S., Usadel B., Fuentes D., Nagy R., . . . Fernie A.R. (2011c) Antisense inhibition of the iron-sulphur subunit of succinate dehydrogenase enhances photosynthesis and growth in tomato via an organic acid-mediated effect on stomatal aperture. The Plant Cell 23, $600-627$.

Araújo W.L., Nunes-Nesi A. \& Williams T.C.R. (2012) Functional genomics tools applied to plant metabolism: a survey on plant respiration, its connections and the annotation of complex gene functions. Frontiers in Plant Science 3, 210.

Arnold A. \& Nikoloski Z. (2013) Comprehensive classification and perspective for modelling photorespiratory metabolism. Plant Biology 15, $667-675$.

Arnold A. \& Nikoloski Z. (2014) Bottom-up metabolic reconstruction of Arabidopsis and its application to determining the metabolic costs of enzyme production. Plant Physiology 165, 1380-1391.

Assmann S.M. (2010) Hope for humpty dumpty: systems biology of cellular signaling. Plant Physiology 152, 470-479.

Baldocchi D.D., Luxmoore R.J. \& Hatfield J.L. (1991) Discerning the forest from the trees: an essay on scaling canopy stomatal conductance. Agricultural and Forest Meteorology 54, 197-226.

Bates G.W., Rosenthal D.M., Sun J., Chattopadhyay M., Peffer E., Yang J., . . . Jones A.M. (2012) A comparative study of the Arabidopsis thaliana guard-cell transcriptome and its modulation by sucrose. PLoS ONE 7, e49641. 
Bauer H., Ache P., Lautner S., Fromm J., Hartung W., Al-Rasheid Khaled A.S. ... Hedrich R. (2013) The stomatal response to reduced relative humidity requires guard cell-autonomous ABA synthesis. Current Biology 23, 53-57.

Bergmann D.C. \& Sack F.D. (2007) Stomatal development. Annual Review of Plant Biology 58, 163-181.

Berry J.A., Beerling D.J. \& Franks P.J. (2010) Stomata: key players in the earth system, past and present. Current Opinion in Plant Biology 13, 232-239.

Bessey C.E. (1898) Some considerations upon the functions of stomata Science 7, 13-16.

Bessire M., Chassot C., Jacquat A.-C., Humphry M., Borel S., Petétot J.M.-C., ... Nawrath C. (2007) A permeable cuticle in Arabidopsis leads to a strong resistance to Botrytis cinerea. The EMBO Journal 26, 2158-2168.

Blatt M.R. (2000) Cellular signaling and volume control in stomatal movements in plants. Annual Review of Cell and Developmental Biology 16, 221-241.

Blatt M.R., Wang Y., Leonhardt N. \& Hills A. (2013) Exploring emergent properties in cellular homeostasis using OnGuard to model $\mathrm{K}^{+}$and other ion transport in guard cells. Journal of Plant Physiology 171, 770-778.

Blonquist J.M. Jr., Norman J.M. \& Bugbee B. (2009) Automated measurement of canopy stomatal conductance based on infrared temperature. Agricultural and Forest Meteorology 149, 1931-1945.

Bordbar A., Monk J.M., King Z.A. \& Palsson B.O. (2014) Constraint-based models predict metabolic and associated cellular functions. Nature Reviews Genetics 15, 107-120.

Boyle N.R., Shastri A.A. \& Morgan J.A. (2009) Network stoichiometry. In Plant Metabolic Networks (ed. J. Schwender), pp. 211-243. Springer, New York, NY, USA.

Buckley T.N. \& Mott K.A. (2013) Modelling stomatal conductance in response to environmental factors. Plant, Cell \& Environment 36, 1691-1699.

Buschhaus C. \& Jetter R. (2011) Composition differences between epicuticular and intracuticular wax substructures: how do plants seal their epidermal surfaces? Journal of Experimental Botany 62, 841-853.

Casson S.A. \& Hetherington A.M. (2010) Environmental regulation of stomatal development. Current Opinion in Plant Biology 13, 90-95.

Chandrasekaran S. \& Price N.D. (2010) Probabilistic integrative modeling of genome-scale metabolic and regulatory networks in Escherichia coli and Mycobacterium tuberculosis. Proceedings of the National Academy of Sciences of the United States of America 107, 17845-17850.

Chandrasekaran S. \& Price N.D. (2013) Metabolic constraint-based refinement of transcriptional regulatory networks. PLoS Computational Biology 9, e1003370.

Chen L.I.N., Dodd I.C., Davies W.J. \& Wilkinson S. (2013) Ethylene limits abscisic acid- or soil drying-induced stomatal closure in aged wheat leaves. Plant, Cell \& Environment 36, 1850-1859.

Chen Z.-H., Hills A., Baetz U., Amtmann A., Lew V. \& Blatt M.R. (2012) Systems dynamic modelling of the stomatal guard cell predicts emergent behaviours in transport, signalling and volume control. Plant Physiology 159, 1235-1251

Cominelli E., Galbiati M., Vavasseur A., Conti L., Sala T., Vuylsteke M., .. Tonelli C. (2005) A guard-cell-specific MYB transcription factor regulates stomatal movements and plant drought tolerance. Current Biology 15, 11961200.

Cowan I.R. (1972) Oscillations in stomatal conductance and plant functioning associated with stomatal conductance: observations and a model. Planta 106, 185-219.

Cowan I.R. \& Farquhar G.D. (1977) Stomatal function in relation to leaf metabolism and environment. Symposia of the Society for Experimental Biology 31, 471-505.

de Oliveira Dal'Molin C.G., Quek L.-E., Palfreyman R.W., Brumbley S.M. \& Nielsen L.K. (2010a) AraGEM, a genome-scale reconstruction of the primary metabolic network in Arabidopsis. Plant Physiology 152, 579-589.

de Oliveira Dal'Molin C.G., Quek L.-E., Palfreyman R.W., Brumbley S.M. \& Nielsen L.K. (2010b) C4GEM, a genome-scale metabolic model to study C4 plant metabolism. Plant Physiology 154, 1871-1885.

Damour G., Simonneau T., Cochard H. \& Urban L. (2010) An overview of models of stomatal conductance at the leaf level. Plant, Cell \& Environment 33, 1419-1438.

De Angeli A., Zhang J., Meyer S. \& Martinoia E. (2013) AtALMT9 is a malate-activated vacuolar chloride channel required for stomatal opening in Arabidopsis. Nature Communications 4, 1804.

Dow G.J. \& Bergmann D.C. (2014) Patterning and processes: how stomatal development defines physiological potential. Current Opinion in Plant Biology 21, 67-74.
Estévez S.R. \& Nikoloski Z. (2014) Generalized framework for contextspecific metabolic model extraction methods. Frontiers in Plant Science 5, 491.

Fahey J.W., Zalcmann A.T. \& Talalay P. (2001) The chemical diversity and distribution of glucosinolates and isothiocyanates among plants. Phytochemistry 56, 5-51.

Famili I. \& Palsson B.O. (2003) The convex basis of the left null space of the stoichiometric matrix leads to the definition of metabolically meaningful pools. Biophysical Journal 85, 16-26.

Feist A.M. \& Palsson B.O. (2010) The biomass objective function. Current Opinion in Microbiology 13, 344-349.

Fernie A.R. \& Martinoia E. (2009) Malate. Jack of all trades or master of a few? Phytochemistry 70, 828-832.

Fernie A.R. \& Stitt M. (2012) On the discordance of metabolomics with proteomics and transcriptomics: coping with increasing complexity in logic, chemistry, and network interactions scientific correspondence. Plant Physiology 158, 1139-1145.

Fernie A.R., Trethewey R.N., Krotzky A.J. \& Willmitzer L. (2004) Metabolite profiling: from diagnostics to systems biology. Nature Reviews Molecular Cell Biology 5, 763-769.

Fuentes D., Meneses M., Nunes-Nesi A., Araújo W.L., Tapia R., Gómez I., . . . Jordana X. (2011) A deficiency in the flavoprotein of Arabidopsis mitochondrial complex II results in elevated photosynthesis and better growth in nitrogen-limiting conditions. Plant Physiology 157, 1114-1127.

Fujii H., Chinnusamy V., Rodrigues A., Rubio S., Antoni R., Park S.-Y., . . Zhu J.-K. (2009) In vitro reconstitution of an abscisic acid signalling pathway. Nature 462, 660-664.

Furon A.C., Warland J.S. \& Wagner-Riddle C. (2007) Analysis of scaling-up resistances from leaf to canopy using numerical simulations. Agronomy Journal 99, 1483-1491.

Ha S., Vankova R., Yamaguchi-Shinozaki K., Shinozaki K. \& Tran L.-S.P. (2012) Cytokinins: metabolism and function in plant adaptation to environmental stresses. Trends in Plant Science 17, 172-179.

Hashimoto M., Negi J., Young J., Israelsson M., Schroeder J.I. \& Iba K. (2006) Arabidopsis HT1 kinase controls stomatal movements in response to $\mathrm{CO}_{2}$. Nature Cell Biology 8, 391-397.

Hedrich R., Marten I., Lohse G., Dietrich P., Winter H., Lohaus G. \& Heldt H.-W. (1994) Malate-sensitive anion channels enable guard cells to sense changes in the ambient $\mathrm{CO}_{2}$ concentration. The Plant Journal 6, 741748 .

Hetherington A.M. \& Brownlee C. (2004) The generation of $\mathrm{Ca}^{2+}$ signals in plants. Annual Review of Plant Biology 55, 401-427.

Hetherington A.M. \& Woodward F.I. (2003) The role of stomata in sensing and driving environmental change. Nature 424, 901-908.

Hills A., Chen Z.-H., Amtmann A., Blatt M.R. \& Lew V.L. (2012) OnGuard, a computational platform for quantitative kinetic modeling of guard cell physiology. Plant Physiology 159, 1026-1042.

Hossain M.A., Munemasa S., Uraji M., Nakamura Y., Mori I.C. \& Murata Y. (2011) Involvement of endogenous abscisic acid in methyl jasmonateinduced stomatal closure in Arabidopsis. Plant Physiology 156, $430-438$

Hosy E., Vavasseur A., Mouline K., Dreyer I., Gaymard F., Porée F., ... Sentenac H. (2003) The Arabidopsis outward $\mathrm{K}^{+}$channel GORK is involved in regulation of stomatal movements and plant transpiration. Proceedings of the National Academy of Sciences of the United States of America 100, 5549-5554.

Hubbard K.E., Siegel R.S., Valerio G., Brandt B. \& Schroeder J.I. (2012) Abscisic acid and $\mathrm{CO}_{2}$ signalling via calcium sensitivity priming in guard cells, new CDPK mutant phenotypes and a method for improved resolution of stomatal stimulus-response analyses. Annals of Botany 109, 5-17.

Ideker T. \& Krogan N.J. (2012) Differential network biology. Molecular Systems Biology 8, 565 .

Israelsson M., Siegel R.S., Young J., Hashimoto M., Iba K. \& Schroeder J.I. (2006) Guard cell ABA and $\mathrm{CO}_{2}$ signaling network updates and $\mathrm{Ca}^{2+}$ sensor priming hypothesis. Current Opinion in Plant Biology 9, 654-663.

Jamshidi N. \& Palsson B.Ø. (2008) Top-down analysis of temporal hierarchy in biochemical reaction networks. PLoS Computational Biology 4, e1000177.

Jarvis P.G. (1976) The interpretation of the variations in leaf water potential and stomatal conductance found in canopies in the field. Philosophical Transactions of the Royal Society of London. Series B 273, 503-610.

Jin X., Wang R.-S., Zhu M., Jeon B.W., Albert R., Chen S. \& Assmann S.M. (2013) Abscisic acid-responsive guard cell metabolomes of Arabidopsis wild-type and gpal G-protein mutants. The Plant Cell 25, 4789-4811. 
Kim T.-H., Böhmer M., Hu H., Nishimura N. \& Schroeder J.I. (2010) Guard cell signal transduction network: advances in understanding abscisic acid, $\mathrm{CO}_{2}$, and $\mathrm{Ca}^{2+}$ signaling. Annual Review of Plant Biology 61, 561-591.

Kleessen S. \& Nikoloski Z. (2012) Dynamic regulatory on/off minimization for biological systems under internal temporal perturbations. BMC Systems Biology 6, 16.

Kleessen S., Araújo W.L., Fernie A.R. \& Nikoloski Z. (2012) Model-based confirmation of alternative substrates of mitochondrial electron transport chain. The Journal of Biological Chemistry 287, 11122-11131.

Kumar R., Arya G.C. \& Bisht N.C. (2014) Differential expression and interaction specificity of heterotrimeric G-protein family in Brassica nigra reveal their developmental and condition-specific roles. Plant and Cell Physiology 55, 1954-1968.

Lawson T. \& Blatt M.R. (2014) Stomatal size, speed, and responsiveness impact on photosynthesis and water use efficiency. Plant Physiology 164, 1556-1570.

Lawson T., Simkin A.J., Kelly G. \& Granot D. (2014) Mesophyll photosynthesis and guard cell metabolism impacts on stomatal behaviour. The New Phytologist 203, 1064-1081.

Lebaudy A., Vavasseur A., Hosy E., Dreyer I., Leonhardt N., Thibaud J.-B., . . Sentenac H. (2008) Plant adaptation to fluctuating environment and biomass production are strongly dependent on guard cell potassium channels. Proceedings of the National Academy of Sciences of the United States of America 105, 5271-5276.

Lee J.M., Gianchandani E.P., Eddy J.A. \& Papin J.A. (2008a) Dynamic analysis of integrated signaling, metabolic, and regulatory networks. PLoS Computational Biology 4, e1000086.

Lee M., Choi Y., Burla B., Kim Y.-Y., Jeon B., Maeshima M., . . Lee Y. (2008b) The ABC transporter AtABCB14 is a malate importer and modulates stomatal response to $\mathrm{CO}_{2}$. Nature Cell Biology 10, 1217-1223.

Leonhardt N., Kwak J.M., Robert N., Waner D., Leonhardt G. \& Schroeder J.I. (2004) Microarray expression analyses of Arabidopsis guard cells and isolation of a recessive abscisic acid hypersensitive protein phosphatase $2 \mathrm{C}$ mutant. The Plant Cell 16, 596-615.

Lewis N.E., Nagarajan H. \& Palsson B.O. (2012) Constraining the metabolic genotype-phenotype relationship using a phylogeny of in silico methods. Nature Reviews. Microbiology 10, 291-305.

Lilley K.S. \& Dupree P. (2007) Plant organelle proteomics. Current Opinion in Plant Biology 10, 594-599.

Liu X., Yue Y., Li B., Nie Y., Li W., Wu W.-H. \& Ma L. (2007) A G proteincoupled receptor is a plasma membrane receptor for the plant hormone abscisic acid. Science 315, 1712-1716.

Mallmann J., Heckmann D., Bräutigam A., Lercher M.J., Weber A.P., Westhoff P. \& Gowik U. (2014) The role of photorespiration during the evolution of $\mathrm{C} 4$ photosynthesis in the genus. Flaveria. eLife 3, e02478.

Martin L., Fei Z., Giovannoni J. \& Rose J.K.C. (2013) Catalyzing plant science research with RNA-seq. Frontiers in Plant Science 4, 66.

Meguro A. \& Sato Y. (2014) Salicylic acid antagonizes abscisic acid inhibition of shoot growth and cell cycle progression in rice. Scientific Reports $\mathbf{4}$, 4555.

Meyer S., De Angeli A., Fernie A.R. \& Martinoia E. (2010) Intra- and extra-cellular excretion of carboxylates. Trends in Plant Science 15, 4047.

Misra B.B., Assmann S.M. \& Chen S. (2014) Plant single-cell and single-celltype metabolomics. Trends in Plant Science 19, 637-646.

Monteith J.L. (1981) Evaporation and surface temperature. Quarterly Journal of the Royal Meteorological Society 107, 1-27.

Mott K.A. (2009) Opinion: stomatal responses to light and $\mathrm{CO}_{2}$ depend on the mesophyll. Plant, Cell \& Environment 32, 1479-1486.

Nakagami H., Sugiyama N., Ishihama Y. \& Shirasu K. (2012) Shotguns in the front line: phosphoproteomics in plants. Plant and Cell Physiology 53, 118124.

Negi J., Moriwaki K., Konishi M., Yokoyama R., Nakano T., Kusumi K., . . Iba K. (2013) A Dof transcription factor, SCAP1, is essential for the development of functional stomata in Arabidopsis. Current Biology 23, 479484.

Nunes-Nesi A., Carrari F., Gibon Y., Sulpice R., Lytovchenko A., Fisahn J., . . Fernie A.R. (2007) Deficiency of mitochondrial fumarase activity in tomato plants impairs photosynthesis via an effect on stomatal function. The Plant Journal 50, 1093-1106.

Osorio S., Do P.T. \& Fernie A.R. (2012) Profiling primary metabolites of tomato fruit with gas chromatography/mass spectrometry. Methods in Molecular Biology 860, 101-109.
Pandey S., Nelson D.C. \& Assmann S.M. (2009) Two novel GPCR-type G Proteins are abscisic acid receptors in Arabidopsis. Cell 136, 136-148.

Pandey S., Wang R.-S., Wilson L., Li S., Zhao Z., Gookin T.E., ... Albert R. (2010) Boolean modeling of transcriptome data reveals novel modes of heterotrimeric G-protein action. Molecular Systems Biology 6, 372.

Park S.-Y., Fung P., Nishimura N., Jensen D.R., Fujii H., Zhao Y., . . Cutler S.R. (2009) Abscisic acid inhibits type 2C protein phosphatases via the PYR/PYL family of START proteins. Science 324, 1068-1071.

Pinheiro C. \& Chaves M.M. (2011) Photosynthesis and drought: can we make metabolic connections from available data? Journal of Experimental Botany 62, 869-882.

Raman K. \& Chandra N. (2009) Flux balance analysis of biological systems: applications and challenges. Briefings in Bioinformatics 10, 435-449.

Roelfsema M.R.G. \& Hedrich R. (2010) Making sense out of $\mathrm{Ca}^{2+}$ signals: their role in regulating stomatal movements. Plant, Cell \& Environment $\mathbf{3 3}, 305$ 321.

Saha R., Suthers P.F. \& Maranas C.D. (2011) Zea mays iRS1563: a comprehensive genome-scale metabolic reconstruction of maize metabolism. PLoS ONE 6, e21784.

Schreiber L. (2010) Transport barriers made of cutin, suberin and associated waxes. Trends in Plant Science 15, 546-553.

Schroeder J.I., Allen G.J., Hugouvieux V., Kwak J.M. \& Waner D. (2001) Guard cell signal transduction. Annual Review of Plant Physiology and Plant Molecular Biology 52, 627-658.

Schroeder J.I., Delhaize E., Frommer W.B., Guerinot M.L., Harrison M.J., Herrera-Estrella L., .. . Sanders D. (2013) Using membrane transporters to improve crops for sustainable food production. Nature 497, 60-66.

Shimazaki K., Doi M., Assmann S.M. \& Kinoshita T. (2007) Light regulation of stomatal movement. Annual Review of Plant Biology 58, 219-247.

Simons M., Saha R., Guillard L., Clément G., Armengaud P., Cañas R., . . . Hirel B. (2014) Nitrogen-use efficiency in maize (Zea mays L.): from 'omics' studies to metabolic modelling. Journal of Experimental Botany 65, 56575671.

Sirichandra C., Wasilewska A., Vlad F., Valon C. \& Leung J. (2009) The guard cell as a single-cell model towards understanding drought tolerance and abscisic acid action. Journal of Experimental Botany 60, 1439-1463.

Song Y., Miao Y. \& Song C.-P. (2014) Behind the scenes: the roles of reactive oxygen species in guard cells. The New Phytologist 201, 11211140.

Suetsugu N., Takami T., Ebisu Y., Watanabe H., Iiboshi C., Doi M. \& Shimazaki K. (2014) Guard cell chloroplasts are essential for blue light-dependent stomatal opening in Arabidopsis. PLoS ONE 9, e108374.

Sweetlove L.J. \& Ratcliffe R.G. (2011) Flux-balance modelling of plant metabolism. Frontier in Plant Science 2, 38.

Tallman G. (2004) Are diurnal patterns of stomatal movement the result of alternating metabolism of endogenous guard cell ABA and accumulation of ABA delivered to the apoplast around guard cells by transpiration? Journal of Experimental Botany 55, 1963-1976.

Tanaka Y., Sano T., Tamaoki M., Nakajima N., Kondo N. \& Hasezawa S. (2005) Ethylene inhibits abscisic acid-induced stomatal closure in Arabidopsis. Plant Physiology 138, 2337-2343.

Temple B.R.S. \& Jones A.M. (2007) The plant heterotrimeric G-protein complex. Annual Review of Plant Biology 58, 249-266.

Töpfer N., Caldana C., Grimbs S., Willmitzer L., Fernie A.R. \& Nikoloski Z. (2013) Integration of genome-scale modeling and transcript profiling reveals metabolic pathways underlying light and temperature acclimation in Arabidopsis. The Plant Cell 25, 1197-1211.

Töpfer N., Kleessen S. \& Nikoloski Z. (2015) Integration of metabolite data into meabolic models. Frontiers in Plant Science 6, 49.

Töpfer N., Scossa F., Fernie A. \& Nikoloski Z. (2014) Variability of metabolite levels is linked to differential metabolic pathways in Arabidopsis's responses to abiotic stresses. PLoS Computational Biology 10, e1003656.

Umezawa T., Sugiyama N., Takahashi F., Anderson J.C., Ishihama Y., Peck S.C. \& Shinozaki K. (2013) Genetics and phosphoproteomics reveal a protein phosphorylation network in the abscisic acid signaling pathway in Arabidopsis thaliana. Science Signaling 6, rs8.

Vanderschuren H., Lentz E., Zainuddin I. \& Gruissem W. (2013) Proteomics of model and crop plant species: status, current limitations and strategic advances for crop improvement. Journal of Proteomics 93, 5-19.

Wang R.-S., Pandey S., Li S., Gookin T., Zhao Z., Albert R. \& Assmann S. (2011) Common and unique elements of the ABA-regulated transcriptome of Arabidopsis guard cells. BMC Genomics 12, 216. 
Wang Y., Papanatsiou M., Eisenach C., Karnik R., Williams M., Hills A., ... Blatt M.R. (2012) Systems dynamic modeling of a guard cell $\mathrm{Cl}^{-}$channel mutant uncovers an emergent homeostatic network regulating stomatal transpiration. Plant Physiology 160, 1956-1967.

Wang Y., Hills A. \& Blatt M. (2014a) Systems analysis of guard cell membrane transport for enhanced stomatal dynamics and water use efficiency. Plant Physiology 164, 1593-1599.

Wang Y., Noguchi K., Ono N., Inoue S., Terashima I. \& Kinoshita T. (2014b) Overexpression of plasma membrane $\mathrm{H}^{+}$-ATPase in guard cells promotes light-induced stomatal opening and enhances plant growth. Proceedings of the National Academy of Science of the United States of America 111, 533538.

Way D.A., Katul G.G., Manzoni S. \& Vico G. (2014) Increasing water use efficiency along the $\mathrm{C} 3$ to $\mathrm{C} 4$ evolutionary pathway: a stomatal optimization perspective. Journal of Experimental Botany 13, 3683-3693.

Young J.J., Mehta S., Israelsson M., Godoski J., Grill E. \& Schroeder J.I. (2006) $\mathrm{CO}_{2}$ signaling in guard cells: calcium sensitivity response modulation, a $\mathrm{Ca}^{2+}$-independent phase, and $\mathrm{CO}_{2}$ insensitivity of the gca2 mutant. Proceedings of the National Academy of Science of the United States of America 103, 7506-7511.

Zhang S., Cai Z. \& Wang X. (2009) The primary signaling outputs of brassinosteroids are regulated by abscisic acid signaling. Proceedings of the National Academy of Science of the United States of America 106, 4543-4548.

Zhao Z., Zhang W., Stanley B.A. \& Assmann S.M. (2008) Functional proteomics of Arabidopsis thaliana guard cells uncovers new stomatal signaling pathways. The Plant Cell 20, 3210-3226.
Zhao Z., Stanley B.A., Zhang W. \& Assmann S.M. (2010) ABA-regulated G protein signaling in Arabidopsis guard cells: a proteomic perspective. Journal of Proteome Research 9, 1637-1647.

Zhu M., Dai S., McClung S., Yan X. \& Chen S. (2009) Functional differentiation of Brassica napus guard cells and mesophyll cells revealed by comparative proteomics. Molecular \& Cellular Proteomics 8, 752-766.

Zhu M., Simons B., Zhu N., Oppenheimer D.G. \& Chen S. (2010) Analysis of abscisic acid responsive proteins in Brassica napus guard cells by multiplexed isobaric tagging. Journal of Proteomics 73, 790-805.

Received 25 October 2014; received in revised form 20 January 2015; accepted for publication 27 January 2015

\section{SUPPORTING INFORMATION}

Additional Supporting Information may be found in the online version of this article at the publisher's web-site:

Table S1. Transcriptomic data from studies on ABA response in guard cells used for a Venn diagramm analysis. 